\title{
A influência de medicamentos na movimentação ortodôntica - Uma análise crítica da literatura
}

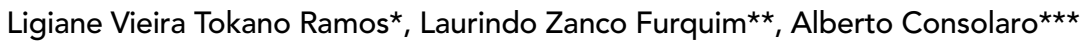

\begin{abstract}
Resumo
Neste trabalho analisou-se criteriosamente a literatura pertinente sobre a influência de medicamentos na movimentação dentária induzida, avaliando os métodos experimentais para correlacioná-los com a aplicabilidade e extrapolação para a clínica ortodôntica. Devido aos trabalhos experimentais serem feitos em animais, que têm um tempo de vida curto, as doses dos medicamentos são elevadas e os períodos de administração muito longos. Portanto, não se pode afirmar sobre qualquer alteração na movimentação dentária induzida causada por algum tipo de medicamento que o paciente faça uso durante o tratamento ortodôntico.
\end{abstract}

Palavras-chave: Medicamentos. Movimentação ortodôntica.

\section{INTRODUÇÃO}

Para que haja entendimento sobre a influência de medicamentos sobre a movimentação ortodôntica, faz-se necessário compreender a biopatologia da movimentação dentária induzida. Esta acontece graças a uma série de eventos biológicos que alteram o nível local de mediadores químicos relacionados à remodelação óssea, como resposta ao estímulo, representado pelas forças aplicadas via aparelho ortodôntico.

Os mediadores químicos são os responsáveis pela intercomunicação celular, ou seja, as células só exercem sua função mediante a liberação destas substâncias, que interagem com os receptores de membrana de outra célula, transmitindo a mensagem seqüencialmente. Quando uma célula está em equilíbrio iônico, libera quantidades mo- deradas de mediadores químicos. Em situações de hipóxia, compressão mecânica ou numa hiperfunção, há uma liberação excessiva destes mediadores. Dentre eles estão as citocinas, os fatores de crescimento, os produtos do ácido aracdônico e outros, como o óxido nítrico, estrógenos, etc.

$\mathrm{O}$ ácido aracdônico é proveniente da quebra de fosfolipídios da membrana celular, pela ação das enzimas fosfolipases, que são ativadas pelo acúmulo de íons cálcio dentro da célula. Estas moléculas de ácido aracdônico sofrem a ação das enzimas cicloxigenases e lipoxigenases, também existentes no citosol, originando as prostaglandinas e os leucotrienes, respectivamente. Portanto, quando uma célula entra em estresse, ocorre uma maior entrada de cálcio extracelular para dentro da célula, pelos canais de cálcio das integrinas.

* Especialista em Ortodontia e Ortopedia Facial pela AMO (Associação Maringaense de Odontologia) / ABO. Consultora Científica de traduções publicadas no site www.dentalpress.com.br

** Especialista em Ortodontia pela PROFIS - USP - Bauru. Professor de Ortodontia do Departamento de Odontologia da Universidade Estadual de Maringá - UEM. Doutor em Patologia Bucal pela Faculdade de Odontologia da Universidade de São Paulo USP - Bauru.

$\star \star \star$ Professor Titular e Chefe do Departamento de Estomatologia da FOB-USP. 
As integrinas são verdadeiras estacas protéicas que unem o meio extracelular com o interior das células. Elas atravessam a membrana celular e estão ligadas ao citosol pelas proteínas do citoesqueleto, que são as responsáveis pela forma da célula.

O processo pelo qual o estímulo físico se transforma em resposta celular, ou mecanotransdução, leva à reabsorção e à aposição óssea e encontra-se fundamentado nesta seqüência de eventos biológicos. A reação inflamatória local, as modificações no citoesqueleto das células, a geração de potenciais elétricos ou piezoeletrecidade e as respostas celulares frente a esses estímulos fazem parte dessa série de eventos, provocando reabsorção e aposição óssea.

Em decorrência da liberação dos mediadores químicos, há o aumento da permeabilidade vascular e formação de exsudato e infiltrado inflamatórios. A presença do exsudato inflamatório caracteriza um $\mathrm{pH}$ ácido, favorecendo a chegada e permanência dos clastos. Além disto, no exsudato encontramos abundantemente a plasmina, que ao interagir com as superfícies dos osteoblastos, induz a liberação de uma colagenase inativa presente em seu citoplasma. A ação simultânea e aditiva da colagenase liberada pelos osteoblastos promove a perda total do osteóide e os cristais de hidroxiapatita ficam expostos, exercendo também quimiotaxia para os clastos.

Os mediadores da osteoclasia, em sua maioria, exercem seu efeito indutor sobre os clastos por via indireta, atuando sobre receptores de superfície dos osteoblastos. Assim ativados, os osteoblastos liberam um fator solúvel para o qual os clastos apresentam receptores específicos.

Os clastos, em sua maioria, não apresentam receptores de superfície para os mediadores da reabsorção, como por exemplo, os produtos do ácido aracdônico, o paratormônio e as citocinas IL-1 e TNF. Foram evidenciados na superfície de osteoclastos receptores para a calcitonina e para estrógenos, sugerindo uma ação direta desses hormônios sobre essas células.

Os avanços da Biologia Molecular, decorrentes do primor tecnológico, traçam perspectivas para a movimentação dentária com auxílio de medicamentos. Por que idealizar um medicamento que atue especificamente sobre o turnover ósseo maxilar? Para controlar a velocidade da movimentação dentária, eventuais desconfortos e influenciar no tempo de tratamento; assim como para atender com segurança aqueles pacientes que fazem uso contínuo ou interrompido de medicamentos para doenças crônicas. Além disto, porque vislumbramos muito em breve a ação destes fármacos para diminuir o risco das reabsorções dentárias na prática diária ortodôntica. Para aplicarmos uma terapêutica adequada, se faz necessário entender como mediadores e medicamentos atuam biologicamente ${ }^{15}$.

\section{REVISÃO DE LITERATURA, ANÁLISE E DISCUSSÃO}

Os mediadores químicos são moléculas geralmente pequenas e produzidas em enorme quantidade, em curtos períodos de tempo. Ao mesmo tempo, são metabolizados ou "consumidos" rapidamente, em segundos, requerendo constante formação para a manutenção dos fenômenos induzidos. Caso o estímulo, para sua produção, desapareça de uma determinada região tecidual, o fenômeno também diminuirá e desaparecerá.

Para que um medicamento possa atuar significantemente em determinado fenômeno biológico requerse uma constante presença molecular deste fármaco, devendo-se indicar sua administração em intervalos de tempo uniformes e constantes, por longo período. Mas pode haver casos em que a finalidade da administração do medicamento seja apenas de eliminar um sintoma eventual e passageiro, como a dor, principalmente após a ativação do aparelho.

Como a dor e a inflamação possuem mediadores comuns, os antiinflamatórios também são analgésicos e vice-versa. Os analgésicos são indicados quando ocorre dor, ou seja, suas doses são aleatórias no tempo ou, no máximo, são distribuídas uniformemente, mas em curtos períodos de tempo. O efeito dos antiinflamatórios requer tempo e dosagens regulares, 
ou seja, não é só o medicamento em si que determinará o efeito analgésico ou antiinflamatório, e sim o tempo, a forma de administração e a sua posologia. Em condições experimentais, a dosagem é alta e o tempo propositadamente prolongado, ainda dentro dos níveis aplicados clinicamente em humanos, por isso, as interferências detectadas são muito importantes, mas nem sempre refletem diretamente o dia-a-dia clínico ${ }^{15}$.

As prostaglandinas são os únicos mediadores químicos da movimentação ortodôntica que têm sido usadas clinicamente e, de acordo com Yamazaki et al..$^{72,73,74}$, numa série de experimentos, demonstraram que a injeção de prostaglandinas aumentava o número de osteoclastos. Trabalhos posteriores mostraram que a injeção de prostaglandinas poderia aumentar a taxa de movimentação dentária em primatas. A ativação da enzima fosfolipase $A$ com conseqüente liberação do ácido aracdônico resulta num aumento da produção de prostaglandina, que em troca, ativa a adenilciclase. Há também um aumento de íons cálcio e a estimulação da síntese de DNA. Mas devido à extensiva gama de moléculas produzidas pelos osteoblastos, é improvável que os prostanóides sejam os únicos produtos de osteoblastos mecanicamente deformados. Realmente, os trabalhos sugerem que um número de fatores de diferentes tamanhos e peso molecular são capazes de simular a reabsorção óssea e são produzidos pelos osteoblastos em resposta à forças mecânicas, demonstrando que estes osteoblastos podem mediar a formação e a reabsorção devido à deformação mecânica. A produção destes fatores depende do tipo e da duração da força aplicada, exatamente quando comparado à experimentação in vivo. As forças intermitentes têm efeitos maiores que as forças contínuas.

Para demonstrar o papel das prostaglandinas na remodelação óssea utilizam-se também os inibidores da enzima cicloxigenase, os antiinflamatórios não esteróides. Experimentos que utilizam estes medicamentos têm mostrado significante diminuição no número de osteoclastos, mas em nem todos estes experimentos ocorre uma diminuição na movimentação dentária, confirmando que as prostaglandinas não são os únicos mediadores da inflamação associada à movimentação dentária induzida ${ }^{63,70}$.

Quanto às vias de administração das prostaglandinas, sistêmica e local, foram avaliadas quanto à eficácia e também com relação aos efeitos adversos provocados. De acordo com Araújo, Prietsch ${ }^{2}$ e Lee $^{37}$, a administração sistêmica apresentou como efeitos indesejáveis uma ação generalizada, sendo parte dela metabolizada nos pulmões e, até agora, não foi encontrada uma solução para que este problema fosse contornado. A via local apresentou efeitos indesejáveis como dor na administração, curta duração e um aumento na tendência à reabsorção radicular ${ }^{2,37}$. Leiker $^{38}$ concorda com os autores citados, quando afirmam que a aplicação local de PGS aumenta a tendência à reabsorção radicular, acrescentando, ainda, que quanto maior a dose e o número de aplicações, maior a tendência à reabsorção, mas discorda deles em relação ao número de aplicações e eficácia, afirmando que a aplicação de prostaglandina mesmo numa baixa concentração e numa única dose já é efetiva na aceleração do movimento dentário. Segundo Tyrovola e Spyropoulos ${ }^{67}$, a administração sistêmica apresenta um efeito melhor que a administração local. Entretanto, a inatividade rápida de prostaglandinas no pulmão, a irritação local e a flebite estão entre os efeitos colaterais da administração intravenosa. Mas, de acordo com os autores, torna-se necessário pesquisas futuras a fim de aprimorar os métodos de aplicação dessas drogas e superar determinados problemas técnicos. Só então os ortodontistas poderão defender o uso de prostaglandinas como um suplemento no tratamento ortodôntico.

Mas a aplicação destes mediadores químicos diretamente nos dentes a serem movimentados, pode revelar-se inviável devido à constante aplicação necessária. Já a administração sistêmica desses produtos pode ser efetiva com o aprimoramento técnico, diminuindo ao máximo os efeitos colaterais, apesar de que esta abordagem está em forma de perspectiva, uma vez que ainda não há protocolos clínicos aplicáveis.

Quanto aos medicamentos inibidores da síntese 
de prostaglandinas, o primeiro a ser descoberto foi o ácido acetil salićlico, seguido pela indometacina, que é mais forte e, hoje em dia, muito pouco utilizada. Segundo Resende ${ }^{58}$ e Ribeiro et al. ${ }^{59}$, o AAS e a indometacina reduzem a quantidade de reabsorção óssea e do movimento dentário.

Já Wong et al. ${ }^{70}$ afirmaram que o AAS, administrado por via oral, em porcos Guinea, não afetuo o movimento dentário, levantando novamente a questão das prostaglandinas não serem os únicos mediadores da reabsorção óssea associadas às forças ortodônticas. Quando a movimentação dentária induzida implica em forças incidindo sobre a região inter-pré-maxilar, segundo Wong, o modelo experimental representado pelo porquinho da Índia oferece vantagens, pois nestes, a sutura já se encontra fusionada no animal adolescente.

Em todos estes trabalhos, porém, temos que observar que os resultados, antes de serem extrapolados para a clínica precisam primeiro ser analisados criteriosamente, pois tratam-se de altas dosagens, como se pode verificar no trabalho de Giunta et al..$^{22}$, onde a dose teve que ser diminuída durante o trabalho devido à perfuração do estômago de um animal por úlcera péptica.

$\mathrm{Na}$ clínica ortodôntica, normalmente não se verifica com freqüência desconforto após a intervenção ortodôntica ou no período de ajuste dos aparelhos. Nos casos esporádicos de dor, indica-se um analgésico comum. No trabalho realizado por Ngan et al. ${ }^{49}$, os autores sugerem que o Ibuprofen é mais eficaz que o ácido acetil salicílico para o alívio de desconfortos após ajustes ortodônticos. Outros autores ${ }^{33,59,60}$, baseados em seus próprios experimentos, sugerem que o Paracetamol seja o melhor antiinflamatório para esta finalidade, porque não interfere na quantidade e nem na velocidade do movimento dentário.

Os corticosteróides são um grupo de compostos derivados do colesterol, que possuem vários efeitos difundidos nos diversos órgãos. Os esteróides sintéticos são usados como antiinflamatórios e imunossupressores no tratamento de diversas doenças crônicas. Eles atuam diretamente inibindo a ação da enzima fosfolipase A2, na degradação dos fosfolipídios da membrana celular, inibindo assim a formação de moléculas do ácido aracdônico e conseqüentemente, de seus produtos, as prostaglandinas e os leucotrienes.

Em altas doses, os esteróides sintéticos levam à perda óssea e osteoporose. Mesmo em baixas dosagens, interferem no ciclo normal de deposição e reabsorção óssea. Em seu experimento com ratos, Ong et al. ${ }^{51}$ verificaram que não houve diferença significativa na movimentação ortodôntica entre os animais tratados com prednisolona e o grupo controle. Estes resultados confirmaram os estudos feitos por Brudvik, Rygh ${ }^{9}$, King e Keeling ${ }^{34}$. O curto período de administração de corticosteróides, nestes estudos, torna remota a possibilidade de hipercortisonismo iatrogênico ou hiperparatireoidismo. Já Ascraft et al. ${ }^{3}$ observaram maior taxa de movimentação ortodôntica em coelhos tratados com acetato de cortisona. Isto se deve ao fato de que neste experimento, o tempo de administração do medicamento foi maior e a dose elevada, induzindo os coelhos à osteoporose. Em contraste, Yamane et al. ${ }^{71}$ mostraram que houve menor taxa de movimentação dentária em gatos tratados com hidrocortisona. Estas diferenças podem ser explicadas pelas variações dentro das espécies animais estudadas, forças usadas para a movimentação e potencial do esteróide usado. No experimento realizado por Ong et al. ${ }^{51}$, onde não houve diferença na taxa de movimentação dentária em ratos tratados com corticosteróides, utilizou-se uma técnica padronizada para indução da movimentação ortodôntica em ratos descrita anteriormente por Brudvik e Rygh $^{9}$. Esta técnica imita a movimentação dentária induzida em humanos.

Em suma, os corticosteróides, quando utilizados experimentalmente, podem modificar a velocidade da movimentação dentária induzida, mas clinicamente, essas modificações não refletem alterações estruturais quanto ao trabeculado ósseo nos maxilares ou quanto ao índice de reabsorção dentária, pois o turnover ósseo dos maxilares é mais lento em 
relação aos demais ossos. Por este motivo, pessoas que fazem uso contínuo de corticóides devido a doenças inflamatórias crônicas e auto-imunes podem ser tratadas ortodonticamente como pacientes normais.

Os bisfosfonatos, pirofosfatos e análogos podem interferir no metabolismo ósseo, por sua alta afinidade com os fosfatos de cálcio. São utilizados no tratamento de hipercalcemia, osteoporose e, geralmente, no tratamento de doenças ósseas metabólicas, que envolvem a reabsorção óssea aumentada. Segundo vários autores ${ }^{1,17,18,30,61,69}$, os bisfosfonatos não somente previnem a perda óssea, mas ativam o aumento da massa e restabelecem as propriedades biomecânicas do esqueleto. O mecanismo de ação parece ser complexo, pois envolve um efeito direto sobre a atividade osteoclástica, um efeito direto e indireto sobre o recrutamento de osteoclastos, o encurtamento de sobrevida dos osteoclastos por apoptose.

De acordo com Adachi et al. ${ }^{1}$, a aplicação tópica dos bisfosfonatos pode reduzir a taxa de movimentação dentária induzida e inibir a recidiva da movimentação conseguida. Esta inibição foi também observada por Igarashi et al. ${ }^{31}$, que demonstrou tanto em experimento com administração tópica como na administração sistêmica, ressaltando que estes resultados são doses dependentes. No entanto, Mazziero $^{40}$ avaliou a ação de um bisfosfonato via oral, e não encontrou diferenças na movimentação dentária nem no grau de reabsorção radicular, sugerindo que pacientes que fazem uso de bisfosfonatos podem ser tratados ortodonticamente como pacientes normais. Todos os autores que realizaram experimentos com os bisfosfonatos concordam que são necessários mais estudos sobre a aplicação clínica destes medicamentos antes de sua utilização com a segurança de que não haverá nenhum efeito sistêmico.

A osteocalcina é a proteína não colagênica mais abundante no tecido ósseo. Devido à sua grande capacidade de associação ao cálcio, a osteocalcina é considerada um regulador negativo para a formação óssea ${ }^{27,56}$. Nos experimentos realizados por Kobaiashi et al..$^{35}$ e Hashimoto et al..$^{26}$, observou-se um aumento na movimentação dentária induzida em ratos tratados com injeção tópica de osteocalcina durante a movimentação ortodôntica. Esse aumento na taxa de deslocamento dentário foi causada pelo intenso recrutamento de osteoclastos na área de pressão. De acordo com estes autores, o efeito da osteocalcina parece não se caracterizar como um efeito secundário, induzido pela própria injeção, pois não houve diferenças entre os grupos de controle e os injetados com esta proteína, em relação à presença de células inflamatórias, como as polimorfonucleares e os linfócitos.

O uso terapêutico da osteocalcina deve ser considerado na clínica ortodôntica, uma vez que os efeitos desta proteína limitam a remodelação óssea. Mundy ${ }^{48}$ já relatou que os terminais de carbono derivados da osteocalcina bovina é um quimiotático para as células da osteoclastogênese. Se a osteocalcina possui a capacidade de induzir a maturação de osteoclastos na mesma extensão em que amadurece proteínas, então o uso deste peptídeo deveria ser praticável na terapia ortodôntica ${ }^{35}$. Hashimoto et al..$^{26}$ concordam com esta suposição, ressaltando que uma única administração de osteocalcina, no estágio inicial da movimentação dentária induzida, seja eficaz, podendo se considerar seu uso terapêutico, com benefícios tanto para o paciente, como para o ortodontista. Contudo, existe a necessidade de mais estudos para que se possa utilizar a osteocalcina na clínica ortodôntica.

Os metabólitos ativos da vitamina D representam os únicos hormônios conhecidos que controlam a absorção de cálcio, que ocorre, primariamente, no duodeno e no jejuno. Em relação à utilização destes metabólitos no controle da movimentação dentária induzida, Collins e Sinclair ${ }^{13}$ demonstraram que a administração tópica de 1,25-diidroxicolecalciferol aumenta o grau do movimento, sem efeito colateral bioquímico, microscópico ou clínico aparentes. Os resultados microscópicos revelaram reabsorção frontal dos ossos alveolares, com a presença de numerosos clastos mononucleados e células precursoras clásticas. Estes resultados foram também observados por Baran et al. ${ }^{4}$, sugerindo que a vitamina $\mathrm{D}$, 
além de aumentar a reabsorção óssea, estimula a aposição óssea no lado de tensão. Contudo, a utilização clínica rotineira da vitamina $\mathrm{D}$ na Ortodontia ainda necessita de maiores investigações, para se determinarem a dosagem correta, a freqüência das administrações e, principalmente, os possivivis efeitos colaterais locais e sistêmicos decorrente da sua utilização em longo prazo ${ }^{41,42}$.

A influência do estrogênio sobre as movimentações dentárias induzidas foi avaliada por Perei$\mathrm{ra}^{52}$ e Vasconcelos ${ }^{68}$. O estrogênio é um hormônio esteróide ovariano, presente no ciclo reprodutivo feminino da menarca à menopausa, que sofre alterações quantitativas durante o ciclo reprodutivo e na gravidez, representando o principal agente contraceptivo encontrado nas formulações dos anticoncepcionais hormonais, via bucal. O efeito benéfico de estrogênios no tecido ósseo é resultante da diminuição do índice de reabsorção óssea.

Tyrovola e Spyropoulos ${ }^{67}$, numa revisão de literatura sobre a influência das drogas sobre a movimentação ortodôntica, referem-se aos estrógenos como inibidores da reabsorção óssea. Segundo estes autores, o uso de estrógenos, teoricamente, diminuiria a velocidade da movimentação dentária induzida quando utilizados como contraceptivos por longos períodos de tempo, podendo influenciar no tratamento ortodôntico. Estas afirmações não se fundamentam em qualquer metodologia utilizada e citada.

Miyajima et al. ${ }^{46}$ relataram um caso clínico, onde também afirmam que o estrogênio diminui a taxa de movimentação ortodôntica, alertando que pacientes que fazem uso de anticoncepcionais hormonais ou reposição estrogênica poderão ter inibição das reabsorções óssea e radicular. Não foram estes os resultados encontrados por Pereira ${ }^{52}$ e Vasconcelos ${ }^{68}$, em seus experimentos com ratas prenhes e que recebiam anticoncepcionais, via oral. Estes pesquisadores mostraram que a ingestão de anticoncepcionais hormonais, bem como o estado de pRenhez, não alteram, exacerbam ou reduzem as alterações celulares e teciduais observadas nas áreas de aplicação de tensão e de pressão dos dentes movimentados ortodonticamente, especialmente com relação ao fenômeno de reabsorção dentária. No trabalho de Franscischone ${ }^{19}$, também não foram detectadas diferenças entre os grupos de pacientes usuárias de contraceptivos e pacientes no climatério quando comparadas ao grupo controle quanto à freqüência de reabsorções dentárias.

A tiroxina representa o principal hormônio liberado pela tireóide na manutenção do metabolismo basal. No experimento realizado por Poumpros et al. ${ }^{54}$, os autores encontraram menor reabsorção radicular em ratos tratados com tiroxina. Mas o período experimental de 10 dias é muito longo para a observação de fenômenos de reabsorção em dentes de ratos, especialmente nos incisivos inferiores de irrupção contínua pelos desgastes incisais. A dose em períodos de 24 horas, na magnitude administrada, é muito diminuta para justificar os resultados e, provavelmente, os resultados seriam diferentes se os dentes examinados fossem os molares destes ratos, pois são dentes semelhantes aos de humanos, quanto à fisiologia da irrupção e formação. Portanto, os dados apresentados por estes autores não são suficientes para justificar uma extrapolação imediata para a administração do hormônio da tireóide, em baixas doses, nos movimentos dentários ortodônticos em humanos como fator de prevenção de reabsorção dentária.

No comentário feito por Christiansen ${ }^{11}$, no final dos trabalhos de Poumpros, Loberg, Engström ${ }^{54} \mathrm{e}$ de Loberg e Engström ${ }^{39}$, ele descreve a imprecisão e o controverso efeito da tiroxina na densidade óssea e elogia o protocolo de "abrir novas perspectivas" para a Ortodontia no nível molecular e hormonal. Povolny ${ }^{55}$, referindo-se a estes mesmos artigos mencionados concorda com a necessidade de mais estudos a respeito do uso da tiroxina nos pacientes ortodônticos.

Com relação à influência do hormônio da paratireóide, o paratormônio (PTH), na movimentação dentária induzida, Soma et al. ${ }^{64,66}$ realizaram dois experimentos, verificando que o PTH aplicado localmente na área de atuação do aparelho 
ortodôntico causava um aumento na velocidade da movimentação dentária. Já nas infusões intermitentes, não houve diferenças entre os grupos tratados com PTH e o grupo controle. Os autores concluem que o paratormônio liberado localmente e continuadamente in situ durante o movimento ortodôntico apresenta perspectiva terapêutica.

A calcitonina estimula a neoformação e inibe a reabsorção óssea. Na revisão de Tyrovola e Spyropoulos $^{67}$, isto atrasaria o tratamento ortodôntico. Esta afirmativa não tem fundamentação revelada ou citada. Os autores mesmos recomendam mais estudos sobre a influência dos medicamentos e dos fatores sistêmicos na movimentação dentária induzida e sugerem uma análise particular de cada caso clínico.

De um modo geral, ler trabalhos sobre a influência de medicamentos na movimentação dentária requer cuidado: são experimentais e para detectar os efeitos dos medicamentos sobre os tecidos, as doses são elevadas e os períodos muito longos, se considerarmos o tempo de vida destes animais. O rato, por exemplo, vive em média 1,5 ano e submetem-no à medicação por 2 a 3 meses, o equivalente a $1 / 6$ da sua vida média. Desta forma, observam-se microscopicamente os efeitos dos medicamentos nos tecidos, mas a extrapolação para a clínica requer uma boa dose de responsabilidade ${ }^{14}$.

\section{CONCLUSÕES}

Um medicamento, para ser capaz de interferir no turnover ósseo maxilar, deve se basear em um efeito altamente específico para esta região ou então sua aplicação deverá ser local. A dose deve ser alta e o período de ação muito prolongado.

Os analgésicos e os antiinflamatórios, apesar de atuarem sobre certos mediadores locais da remodelação óssea, são administrados em doses pequenas e em curtos períodos de tempo, não interferindo significantemente na velocidade da movimentação dentária.

Os corticosteróides podem levar à osteoporose quando administrados por longos períodos e doses elevadas, mas nos maxilares, isto só acontecerá em uma fase muito avançada, quando a doença já tiver sido detectada.

Os trabalhos experimentais aqui relatados são feitos com animais experimentais e para detectar estes efeitos dos medicamentos sobre os tecidos, as doses são elevadas e os períodos muito longos, uma vez que estes animais têm um tempo de vida curto.

Portanto, não se pode afirmar sobre qualquer alteração na movimentação dentária induzida causada por algum tipo de medicamento que o paciente faça uso durante o tratamento ortodôntico.

\title{
The influence of medication on orthodontic tooth movement - a critical review of the literature
}

\begin{abstract}
In this work the pertinent literature concerning the influence of medication in the induced dental movement appraising the experimental methods to correlate them with the applicability and extrapolation was critically analyzed for the orthodontic clinic. Owed the experimental works they be done in animals, that they have a time of life short, the doses of the medicines are high and the very long administration periods. Therefore, one cannot affirm about any alteration in the induced dental movement caused by some medication type that the patient makes use during the orthodontic treatment.
\end{abstract}

Key words: Medication. Orthodontic movement. 


\section{REFERÊNCIAS}

1. ADACHI, H. et al. Effects of topical administration of a bisphosphonate (Risedronate) on orthodontic tooth movements. J Dent Res, Washington DC, v. 73, no. 8, p.1478-1786, Aug. 1994.

2. ARAÚJO, F. F; PRIETSCH, J. R. Utilização clínica de mediadores químicos da inflamação (prostaglandinas) no tratamento ortodôntico. Ortodontia Gaúcha, Porto Alegre, v. 4, n. 2, p.163173, jul./dez. 2000.

3. ASHCRAFT, M. B.; SOUTHARD, K. A.; TOLLEY, E. A. The effect of corticosteroid-induced osteoporosis on orthodontic tooth movement. Am J Orthod Dentofacial Orthop, St. Louis, v. 102 no. 4 , p. 310-319, Oct. 1992

4. BARAN, S.; HAMAMCI, O.; AKALAR, M. An investigation of the effects of experimental tooth movement in rats. J Marmara University Dental Faculty, Istanbul, v. 2, no. 2-3, p. 557-561, Sept. 1996.

5. BAUMRIND, S. A reconsideration of the propriety of the "pressure-tension" hypothesis. Am J Orthod Dentofacial Orthop, St. Louis, v. 55, no. 1, p. 12-22, Jan. 1969

6. BERTOZ, F. A.; MENDONÇA, M. R.; CUOGHI, O A., PERCINO$\mathrm{TO}, \mathrm{C}$. Efeito da prostaglandina E1 e da indometacina na movimentação ortodôntica em cães: estudo clínico e histológico. Ortodontia, São Paulo, v. 23, n. 3, p.16-24, set./dez. 1990

7. BOLLEN, A. M. Commentary: Orthodontic treatment for a patient after menopause. Angle Orthod, Appleton, v. 66, no. 3, p. 179-180, 1996.

8. BURROW, S. J.; SAMMON, P. J.; TUNCAY, O. C. Effects of diazepam on orthodontic tooth movement and alveolar bone camp levels in cats. Am J Orthod Dentofacial Orthop, St. Louis, v. 90, no. 2, p. 102-105, Aug. 1986.

9. BRUDVIK, P.; RYGH, P. Root resorption after local injection of prostaglandin E2 during experimental tooth movement. Eur J Orthod, London, no. 13, p. 255-263, 1991

10. CHAO, C. et al. Effects of prostaglandin E2 on alveolar bone resorption during orthodontic tooth movement. Acta Anat, Basel, v. 132 , no. 4 , p. 304-309, Aug. 1988.

11. CHRISTIANSEN, R. L. Commentary: tyroxine administration and its effects on root resorption. Angle Orthod, Appleton, v. 64, no. 5, p. 399-400, May 1994.

12. CHUMBLEY, A. B.; TUNCAY, O. C. The effect of indomethacin (an aspirin-like drug) on the rate of orthodontic tooth movement. Am J Orthod Dentofacial Orthop, St. Louis, v. 89, p. 312-314, Apr. 1986.

13. COLLINS, M. K.; SINCLAIR, P. M. The local use of vitamin $D$ to increase the rate of orthodontic tooth movement. Am J Orthod Dentofacial Orthop, St. Louis, v. 94, no. 4, p. 278-284, Oct. 1988.

14. CONSOLARO, A. Medicamentos versus Ortodontia. R Dental Press Ortodon Ortop Facial, Maringá, v. 2, n. 2, p. 100, abr./maio 2003

15. CONSOLARO, A. Reabsorções dentárias nas especialidades clínicas. Maringá: Dental Press, 2002.

16. DUURSMA, S. A et al. Estrogen and bone metabolism. Obstet Gynecol Surv, Baltimore, v. 47, no. 1, p. 38-44, Jan. 1992.

17. ENGSTRÖM, C.; GRANSTRÖM, G.; THILANDER, B. Effect of orthodontic force on periodontal tissue metabolism. A histologic and biochemical study in normal and hypocalcemic young rats. Am J Orthod Dentofacial Orthop, St. Louis, v. 93, no. 6, p. 486-495, June 1988.

18. FLEISCH, H. Mechanisms of action of the bisphosphonates. Medicine, New York, v. 57, p. 65-75, 1997.

19. FRANCISCHONE, T. R. C. G. Reabsorção dentária: determinação de sua freqüência em pacientes com endocrinopatias. 2002. Tese (Doutorado) - Faculdade de Odontologia de Bauru, Universidade de São Paulo, Bauru, 2002.

20. FUROUIM, L. Z. Perfil endocrinológico de pacientes ortodônticos com e sem reabsorções dentárias: correlação com a morfologia radicular e da crista óssea alveolar. 2002. Tese (Doutorado) - Faculdade de Odontologia de Bauru, Universidade de São Paulo, Bauru, 2002.
21. GIANELLY, A. A.; SCHNUR, R. M. The use of parathyroid hormone to assist orthodontic tooth movement. Am J Orthod Dentofacial Orthop, St. Louis, v. 55, no. 3, p. 305, Mar. 1952

22. GIUNTA, D. et al. Influence of indomethacin on bone turnover related to orthodontic movement in miniature pigs. Am J Orthod Dentofacial Orthop, St. Louis, v.105, no. 4, p. 369-374, Abr. 1994.

23. GOLDIE, R. S.; KING, G. J. Root resorption and tooth movement in orthodontically treated calcium deficient and lactating rats. Am J Orthod, St. Louis, v. 85, no. 5, p. 424-430, May 1984.

24. GOODMAN, L. S.; GILMAN, A. As bases farmacológicas da terapêutica. 6. ed. Rio de Janeiro: Guanabara, 1983, v. 2 p. 775-1559.

25. GRIER, R. L.; WISE, G. E. Inhibition of tooth eruption in the rat by a bisphosphonate. J Dent Res, Chicago, v. 77, no. 1, p. 8-15, Jan.1998.

26. HASHIMOTO, F. et al. Administration of osteocalcin accelerates orthodontic tooth movement induced by a closed coil spring in rats. Eur J Orthod, London, v. 23, p. 535-545, 2001.

27. HAUSCHKA, et al. Direct identification of the calcium binding amino acid-carboxyglutamate in mineralized tissue. Proc Nad Acad Sci, New York, v. 72, no. 10, p. 3925-3929, Oct. 1975.

28. HELLSING, E.; HAMMARSTRÖM, L. The effects of pregnancy and fluoride on orthodontic tooth movements in rats. Eur J Orthod, London, v. 13, no. 3, p. 223-230, June 1991.

29. HILL, P. A. Bone remodelling. Br J Orthod, London, v. 25, no. 2, p. 101-107, May 1998

30. HUGHES, D. et al. bisphosphonates promote apoptose in culture osteoclasts in vitro and in vivo. J Bone Miner Res, Washington, DC, v. 10, no. 20, p. 478-487, 1995.

31. IGARASHI, K. et al. Anchorage and retentive effects of a bisphosphonate (AHBuBP) on tooth movements in rats. Am J Orthod Dentofacial Orthop, St. Louis, v. 106, p. 279-289, 1994.

32. KAMATA, M. Effect of parathyroid hormone on tooth movement in rats. Bull Tokyo Med Dent Univ, Tokyo, v. 19, no. 4, p. 411 425, Dec. 1972.

33. KEHOE, M. J. et al. The effect of acetaminophen, ibuprofen, and misoprostol on prostaglandin E2 synthesis and the degree and rate on orthodontic tooth movement. Angle Orthod Appleton, v. 66, no. 5, p. 339-350, 1996.

34. KING, G. J.; KEELING, S. D. Orthodontic bone remodeling in relation to appliance decay. Angle Orthod, Appleton, v. 65, no. 2, p.129-140, 1995.

35. KOBAYASHI, Y. et al. Effects of local administration of osteocalcin on experimental tooth movement. Angle Orthod, Appleton, v. 68, no. 3, p. 259-266, 1998.

36. KYRKANIDES, S., O'BANION, M. K.; SUBTELNY, J. D. Nonsteroidal anti-inflammatory drugs in orthodontic tooth movement: Metalloproteinase activity and collagen synthesis by endothelial cells. Am J Orthod Dentofacial Orthop, St. Louis, v. 118, p. 203-209, 2000.

37. LEE, W. Experimental study of the effect of prostaglandin administration on tooth movement- with particular emphasis on the relationship to the method of PGE1 administration. Am J Dentofacial Orthop, St. Louis, v. 98, no. 3, p. 231-241, Sept. 1990.

38. LEIKER, B. J. et al. The effect of exogenous prostaglandins on orthodontic tooth movement in rats. Am J Dentofacial Orthop, St. Louis, v. 108, no. 8, p. 380-388, Oct. 1995.

39. LOBERG, E. L.; ENGSTRÖM, C. Thyroid administration to reduce root resorption. Angle Orthod, Appleton, v. 64, no. 5, p. 395-400, May 1994.

40. MAZZIERO, E. T. Bisfosfanatos e movimentação dentária induzida: avaliação de seus efeitos. 1999. $152 \mathrm{f}$. Tese (Doutorado) - Faculdade de odontologia de Bauru, Universidade de São Paulo, Bauru, 1999

41. MAZZIERO, E. T.; CONSOLARO, A. A dinâmica óssea e o movimento ortodôntico. Parte I - Revisão de literatura. Revista do CROMG, Belo Horizonte, v. 6, n. 1, p. 10-17, jan./abr. 2000. 
42. MAZZIERO, E. T.; CONSOLARO, A. A dinâmica óssea e o mo vimento ortodôntico. Parte II - O metabolismo do cálcio e a influência das drogas. Revista do CROMG, Belo Horizonte, v. 6, n. 2, p. 106-112, maio/ago., 2000.

43. MEGHJI, S. Bone remodelling. Br Dent J, London, v. 21 no. 172, p. 235-242, 1992.

44. MIDGETT, R. J.; SHAYE, R.; FRUGE, J. F. The effect of altered bone metabolism on orthodontic movement. Am J Orthod Dentofacial Orthop, St. Louis, v. 80, no.3, p. 256-262, Sept. 1981.

45. MITSUYA, K. The effect of high protein low calcium on tooth movement in the rat. Nippon Kyosei Shika Gakkai Zasshi Tokyo, v. 41, no. 1, p. 46-70, Mar. 1982

46. MIYAJIMA, K.; NAGAHARA, K.; LIZUKA, T. Orthodontic treatment for a patient after menopause. Angle Orthod, Appleton, v. 66, no. 3, p. 173-178, 1996.

47. MOHAMMED, A.; TATAKIS, D.; DIZIAK, R. Leukotrienes in orthodontic tooth movement. Am J Orthod Dentofacial Orthop St. Louis, v. 95, no. 3, p. 231-237, Mar. 1989

48. MUNDY, G. R. Inflammatory mediators and the destruction of bone. J Periodont Res, Copenhagen, v. 26, no. 3, p. 212-217 May 1991.

49. NGAN, P. et al. The effect of ibuprofen on the level of discomfort in patients undergoing orthodontic treatment. Am J Orthod Dentofacial Orthop, St. Louis, v. 106, no. 1, p. 88-95, July 1994.

50. OHKAWA, S. Effects of orthodontic forces and anti-inflammatory drugs on the mechanical strength of the periodontum in the rat mandibular first molar. Am J Orthod Dentofacial Orthop, St. Louis, v. 81, no. 6, p. 498-502, June 1982.

51. ONG, C. K. L. et al. Orthodontic tooth movement in the prednisolone - treated rat. Angle Orthod, Appleton, v. 70, no. 2 p. $118-125,2000$.

52. PEREIRA, A. A. C. Avaliação microscópica da influência de anticoncepcional e gravidez na movimentação dentária induzida, em especial nos fenômenos da reabsorção dentária. 1995. Dissertação (Mestrado) - Faculdade de Odontologia de Bauru, Universidade de São Paulo, Bauru, 1995.

53. PEREIRA, S. L. S. et al. Efeito da calcitonina de salmão sobre a cicatrização de defeitos ósseos. Estudo radiográfico e histológico em coelhos. Rev Odontol UNESP, São Paulo, v. 26, n. 2, p. 471-488, 1997

54. POUMPROS, E.; LOBERG, E.; ENGSTRÖM, C. Thyroid function and root resorption. Angle Orthod, Appleton, v. 64, no. 5 p. 389-393, May 1994

55. POVOLNY, B. Commentary: thyroid function and root resorption. Angle Orthod, Appleton, v. 64, no. 5, p. 394, May 1994.

56. PRICE, P. A.; WILLIAMSON, M. K. Primary structure of bovine matrix Gla protein: a new vitamin K-dependent bone protein. J Biol Chem, Baltimore, v. 260, no. 28, p. 14971-14975, Dec. 1985.

57. PROFFIT, W. R. et al. Ortodontia contemporânea. 2 ed. Rio de Janeiro: Guanabara, 1995. cap. 9, p. 244-264. As bases biológicas da terapia ortodôntica.

58. RESENDE, A. C. A influência do ácido acetilsalicílico no movimento dentário ortodôntico. 1999. 152 f. Dissertação (Mestrado) - Faculdade de Odontologia, Universidade Federal do Rio de Janeiro, 1999.
59. RIBEIRO, A.; CUOGHI, O. A. ; RIBEIRO, F. C. Influência de diferentes drogas sobre a movimentação dentária induzida. R Dental Press Biologia Oral, Maringá, v. 1, n.1, p. 5-16. jan./abr. 2000.

60. ROCHE, J.; CISNEROS, G.; ACS, G. The effect of acetaminophen on tooth movement in rabbits. Angle Orthod, Appleton, v. 67, no. 3, p. 231-236, July 1997.

61. RODAN, G. A. Bone mass homeostasis and bisphosphonate action. Bone, Elmsford, v. 20, no. 1, p. 1-4, Jan. 1997.

62. SANDY, J. R.; HARRIS, M. Prostaglandins and tooth movement. Eur J Orthod, London, v. 6, no. 3, p. 175-182, Aug. 1984.

63. SANDY, J. R. et al. Recent advances in understanding mechanically induced bone remodeling and their relevance to orthodontic theory and practice. Am J Orthod Dentofacial Orthop, St, Louis, v. 103, no. 3, p. 212-222, Mar. 1993.

64. SOMA, S. et al. Effects of continuous infusion of PTH on experimental tooth movement in rats. J Bone Miner Res, Washington, DC, v. 14, no. 4, p. 547-554, Apr. 1999.

65. SELAIMEN, C. R. P. et al. Ortodontia Gaúcha, Porto Alegre, v. 1, n. 2, maio/dez. 1997.

66. SOMA, S. et al. Local and chronic application of PTH accelerates tooth movements in rats. J Dent Res, Chicago, v. 79, no. 9, p. 171, Sept. 2000

67. TYROVOLA, J. B. SPYROPOULOS, M. N. Effects of drugs and systemic factors on orthodontic treatment. Quintessence Int Berlin, v. 28, no. 5, p. 365-371, May 2001.

68. VASCONCELOS, M. H. F. Análise morfológica comparativa do periodonto de sustentação submetido a forças biologicamente excessivas em ratas adultas sem e sob o uso de anticoncepcionais e em ratas prenhes. 1996. 148 f. Dissertação (Mestrado em Patologia Bucal) - Faculdade de Odontologia de Bauru, Universidade de São Paulo, Bauru, 1996.

69. WARITA, $H$. et al. Effects of local injection with bisphosphonate (HEBP) on experimental tooth movement. J Jpn Orthod Soc, Tokyo, v. 51, no. 4, p. 292-301, 1992.

70. WONG, A.; REYNOLDS, E. C.; WEST, V. C. The effect of acetylsalicylic acid on orthodontic tooth movement in the guinea pig. Am J Dentofacial Orthop, St. Louis, v. 102, no. 4, p. 246-250, Apr. 1999

71. YAMANE, A.; FUKUI, T.; CHIBA, M. In vitro measurement of orthodontic tooth movement in rats given $B$ - aminoproprionitrile or hydrocortisone using a time-lapse videotape recorder. Eur J Orthod, London, v. 19, no.1, p. 21-28, Feb. 1997.

72. YAMAZAKI, K. The role of cyclic AMP, calcium and prostaglandins in the induction of osteoclastic bone resorption associated with experimental tooth movement. J Dent Res, Chicago, v. 8 no. 62, p. 877-881, Aug. 1983.

73. YAMAZAKI, K.; SHIBATA, Y.; FUKUHARA, T. The effect of prostaglandins on experimental tooth movement in monkeys (Macaca fuscata). J Dent Res, Chicago, v. 61, no. 12, p. 1444-1446, Dec. 1982.

74. YAMAZAKI, K. et al. Clinical application of prostaglandin E1 (PGE1) upon orthodontic tooth movement. Am J Orthod Dentofacial Orthop, St. Louis, v. 85, no. 6, p. 508-518, June 1984.
Endereço para correspondência

Ligiane Vieira Tokano Ramos

Rua Luiz Gama, 933 - sala 2

Maringá - PR

CEP: $87013-320$ 